\title{
Maternal depression and anxiety associated with dental fear in children: a cohort of adolescent mothers in Southern Brazil
}

\begin{abstract}
Vanessa Polina Pereira COSTA ${ }^{(a)}$ Marcos Britto CORREA(b) Marília Leão GOETTEMS (b) Ricardo Tavares PINHEIRO(c) Flávio Fernando DEMARCO(b)
\end{abstract}

\footnotetext{
(a) Universidade de Brasília - UnB, Department of Pediatric Dentistry, Brasília, DF, Brazil.

(b) Universidade Federal de Pelotas - UFPel, Post-Graduate Program in Dentistry, Pelotas, RS, Brazil.

(c) Universidade Católica de Pelotas - UCPel, Post-Graduate Program in Health and Behavior, Pelotas, RS, Brazil .
}

Declaration of Interest: The authors certify that they have no commercial or associative interest that represents a conflict of interest in connection with the manuscript.

Corresponding author:

Vanessa Polina Pereira Costa Email: polinatur@yahoo.com.br

https://doi.org/10.1590/1807-3107BOR-2017.vol31.0085
Abstract: Exposure to maternal symptoms of depression/anxiety has long-term negative consequences for child development, regardless of the contextual risk. The objective of this study was to investigate the relationship of the symptomatology of persistent maternal depression and anxiety with child dental fear. This study was nested in a cohort of adolescent mothers in southern Brazil. Symptomatology of maternal depression and anxiety was assessed during pregnancy and postpartum, when the mothers' children were 24-36 months old, using Beck Depression Inventory and Beck Anxiety Inventory. The mothers answered a questionnaire to assess dental fear in their children, and to obtain socioeconomic and demographic data. Both mothers and their children were submitted to clinical oral examination $(n=540$ dyads) to obtain oral health data. Multivariate hierarchical Poisson regression analysis was used to determine associations $(\mathrm{p}<0.05)$. At data collection, the prevalence of maternal depressive symptoms was $39.1 \%$, and anxiety was observed in $27.8 \%$ of the mothers, whereas $21.6 \%$ of the children presented dental fear. In the adjusted analysis, children's dental fear was positively associated with mothers' presenting depressive symptomatology and caries experience. The depression symptomatology trajectory was not associated with dental fear, whereas mothers with persistent symptoms of anxiety reported higher prevalence of dental fear toward their offspring. The findings of symptomatology of maternal depression observed at data collection and persistence of anxiety may negatively impact the child's perception of dental fear. Mothers are the main caregivers and primary models responsible for transmitting health-related behaviors; consequently, mental disorders affecting mothers may negatively impact their children.

Keywords: Mental Disorders; Child; Dental Anxiety; Anxiety; Depressive Disorder.

\section{Introduction}

Depression in adolescents is the most frequent psychiatric condition, Accepted for publication: July 27, 2017 Last revision: August 23, 2017 especially among women of childbearing age. ${ }^{1}$ Pregnancy in adolescents is considered a risk factor for symptoms of depression, considering that 
pregnant adolescents present a higher prevalence of depressive symptoms than nonpregnant adolescents (16-44\% vs 5-20\%). ${ }^{2}$ High levels of anxiety symptoms are also common during pregnancy ${ }^{3}$ and in the first year postpartum. ${ }^{4}$ Moreover, continuous exposure to maternal symptoms of depression/anxiety has long-term negative consequences for child development, regardless of the contextual risk. ${ }^{5}$

According to the attachment theory, ${ }_{1}^{6}$ human beings are naturally endowed with an attachment behavioral system that motivates people to bond with others in their environment, and to seek out these "attachment figures" when they become distressed. Mothers are the main "attachment figure," but if they present symptoms of depression, suboptimal interactions between mothers and infants could occur, with the children presenting more anxiety disorders and insecure attachment. ${ }^{7}$ Offspring of anxious parents show a pattern of psychophysiological reactivity to fearful stimuli, which could be a risk factor for the development of anxiety disorders. ${ }^{8}$

Alterations during adolescence, associated with depression symptoms, especially loss of interest or pleasure, may also lead to disinterest of the mother to take care of her child. Insecurity toward attachment may also influence the way women subjectively experience their pregnancy, presenting ambivalent emotions toward the fetus and their future maternal role. These processes may be more relevant for young mothers, considering that a strong association between insecurity of attachment and internalizing of problems, including depression, has been found in adolescents and young adults. ${ }^{9}$

Children whose parents present anxiety symptoms are at greater risk of developing fearfulness and anxiety themselves. In addition, maternal dental anxiety status and maternal psychiatric morbidity were closely related to child dental anxiety status. ${ }^{10}$ Regardless of whether this maternal ability is perceived in terms of personality strength or containment of affect, the most important consideration is how the functionality of the mother's personality enables her child to cope with internal fears caused by situations such as dental treatment. ${ }^{11}$ Dental anxiety and dental fear are often referred to synonymously, and their presence in early childhood has been associated to the maternal oral condition, the presence of dental caries, and dental pain..$^{12}$ A negative dental experience can create dental fear, and, consequently, avoidance of a dental appointment and poor oral health conditions. ${ }^{13}$

Previous results have shown that dental anxiety is related to general anxiety and high levels of general fearfulness. ${ }^{14}$ However, there is lack of information in the literature concerning the potential role of maternal depression or anxiety symptoms and its persistence in the development of dental fear in the child. Therefore, the objective of this study was to investigate the relationship between maternal depression and anxiety symptoms, and the cumulative episodes of these symptoms during pregnancy and postpartum (children at 24-36 months), and in the development of dental fear in the child.

\section{Methods}

\section{Study design and population}

This study was done in Pelotas, a city of 342,053,000 inhabitants, located in southern Brazil. The cohort included adolescent mothers (aged 11 to 19 years old) studied ever since pregnancy and during prenatal visits. All the participants enrolled in this study attended prenatal care in the public health care system (SUS), including 47 basic health care units and 3 outpatient centers, with about $95 \%$ of the follow-up provided by SUS. More details about the methodology of the study can be found elsewhere. ${ }^{15}$

The pregnant women were recruited between October 2009 and March 2011. The sample size was calculated based on the major aim of the study, that is, to detect the prevalence of mood disorders in a population of pregnant adolescents, by using the STATCALC tool of the Epi Info software (Center for Disease Control and Prevention, Atlanta, GA, USA). The required sample size was determined as being 758. Fifteen percent was added to offset eventual losses and refusals, and ultimately obtain a sample size of 871 participants. The present study was carried out when the children were between 24 and 36 months old; data collection occurred between June 2012 and March 2014. Maternal depression and anxiety up to the $31^{\text {st }}$ week of gestation were the only data used from previous evaluations (T1). The second evaluation (T2) 
considered the mother's data at the $32^{\text {nd }}$ to $37^{\text {st }}$ week of gestation, and the third evaluation (T3) analyzed 30 to 60 days postpartum; however, the data from T2 and T3 not were used in this study. The other data included in this study refer to assessments of the children between 24 and 36 months (T4).

\section{Data collection}

A pretest questionnaire was used to collect all the required and relevant information regarding personal data, socioeconomic profile, family income, educational level of the mothers, and sex of the children. The fieldwork team consisted of five graduate dental students from the Federal University of Pelotas (UFPel), who acted as examiners, and five graduate psychologist students, who served as interviewers assigned to conduct the interviews at the psychology clinic of the Catholic University of Pelotas. All the examiners and interviewers were trained, and the oral conditions were calibrated according to previously described methodology. ${ }^{16}$ Examiner reliability was calculated using weighted kappa tests and intraclass correlation coefficients when appropriate. The mean kappa value was 0.83 for dental caries. Agreement was measured by a trained dentist with experience in epidemiological investigations, using the gold standard.

\section{Outcome variable}

\section{Dental fear in children}

The Dental Anxiety Question (DAQ) validated by Neverlien ${ }^{17}$ and adapted by Oliveira and Colares ${ }^{18}$ consists of a single question: Do you think your child is afraid of going to the dentist? The following possible answers were provided: a. "no," b. "yes, a little," c. "yes," and d. "yes, a lot." The categories were dichotomized into "No, my child does not have dental fear" (for answers 1 and 2), and "Yes, my child has dental fear" (for answers 3 and 4).

\section{Variables of interest}

\section{Maternal anxiety}

The Beck Anxiety Inventory (BAI) ${ }^{19}$ consists of 21 questions about how the individual felt in the previous week, expressed in terms of common anxiety symptoms (such as sweating and feeling distressed). Each question has four possible answers. The BAI has a maximum score of 63; scores above 11 indicate the presence of anxiety disorders, and scores below this point indicate absence of anxiety.

\section{Maternal depression}

The Beck Depression Inventory (BDI)- $\mathrm{II}^{20}$ is a widely used, 21-item self-report inventory designed to measure the severity of depressive symptoms, as analyzed by such factors as mood, pessimism, sense of failure, and somatic symptoms. Scores higher than 12 indicate the presence of depressive symptoms, and scores below this point indicate the absence of depressive symptoms.

\section{Trajectories of depression and anxiety symptomatology}

Data on depression and anxiety symptoms were collected up to the $31^{\text {st }}$ week of gestation (T1), and at data collection time (T4). The trajectories constructed were based on these two moments, and were scaled as follows: "always depressed" or "always anxious," "never depressed" or "never anxious," "depressed/not depressed" or "anxious/not anxious," and "not depressed/depressed" or "not anxious/anxious."

\section{Maternal dental anxiety}

The Dental Anxiety Scale (DAS) ${ }^{21}$ is a formal scale for the assessment of dental anxiety. The questionnaire has four questions regarding a mother's feelings in relation to a dental appointment. The total scores may range from 4 to 20 and are scaled as mild (up to 11 points), moderate (12-14 points), and severe ( $\geq 15$ points) anxiety.

\section{Mother's dental caries experience (DMFT)}

The clinical examination was carried out with oral clinical mirrors and CPI probes, under artificial light provided by a headlamp, with the mother sitting in the dental chair. Maternal dental caries was determined by using the DMFT index recommended by the World Health Organization (WHO), ${ }^{22}$ and the outcome was dichotomized into "without dental caries" $(\mathrm{DMFT}=0)$ and "with dental caries" (DMTF $\geq 1$ ). 


\section{Child's dental caries experience (DMFS)}

The child was seated in a chair facing away from the examiner, and reclining in such a manner that her or his head rested on the examiner's lap. The clinical examination was carried out with oral clinical mirrors and CPI probes, under artificial light. Early childhood caries was defined as the presence of caries experience in the child (DMFS $\geq 1$ ).

\section{Child dentist visit}

The data was collected from the questionnaire addressing mothers, and consisted of one question: "Has your child ever visited a dentist? Yes or No?"

\section{Co-variables}

Regarding maternal schooling, the number of school years was considered and dichotomized into $\leq 4$ years and 5-8 years. Data on family income were collected based on criteria for economic classification used in Brazil (CCEB), which seeks to estimate the purchasing power of individuals and urban families, and which categorizes them into economic classes $(\mathrm{A}, \mathrm{B}, \mathrm{C}, \mathrm{D}$, and $\mathrm{E}){ }^{23}$

\section{Sample size calculation}

The sample size was large enough to have a power of $80 \%$, to detect a prevalence ratio of 1.6 or greater, considering a $26.5 \%$ prevalence of dental fear in children from depressive mothers, a 0.64 ratio of exposed/ nonexposed groups, and a 95\% confidence interval.

\section{Statistical methods}

STATA software version 10.0 was used to perform the analyses. Associations between variables were tested with the chi-square test. In the multivariate analysis, Poisson regression with robust variance was used to estimate the prevalence ratios and $95 \% \mathrm{CI}$.

The variables in the final model were selected by using a hierarchical approach, in which the variables were ordered into levels to determine their inclusion in the statistical analysis. All associations were adjusted for covariates positioned in the same and upper levels of the model. In each level, the variable selection followed the stepwise backward method (Figure 1). For the variables to be included in the model, they had to have a p-value $\leq 0.25$. The prevalence ratios and $95 \% \mathrm{CI}$ were assessed. The theoretical model is presented in Figure 1.

\section{Ethical aspects}

This study was approved by the Research Ethics Committee of the Federal University of Pelotas (protocol 194/2011). The research was conducted in full accordance with the World Medical Association Declaration of Helsinki. The parents/guardians of the adolescent mothers under 18 years of age provided written informed consent. Mothers over 18 years of age provided written informed consent for themselves as well as for their children. Children and mothers diagnosed with problems were also referred for treatment.

\section{Results}

Figure 2 shows the flowchart of the study. Of the 871 mothers evaluated during pregnancy, a total of 540 , together with their offspring (dyads), were included in the present evaluation, resulting in a response rate of $62 \%$. We were able to contact 584 mothers, but there were 44 losses for the following reasons: death of mother (2), death of baby (9), refusal to participate (22), and failure to appear in 3 consecutive scheduled examinations (11).

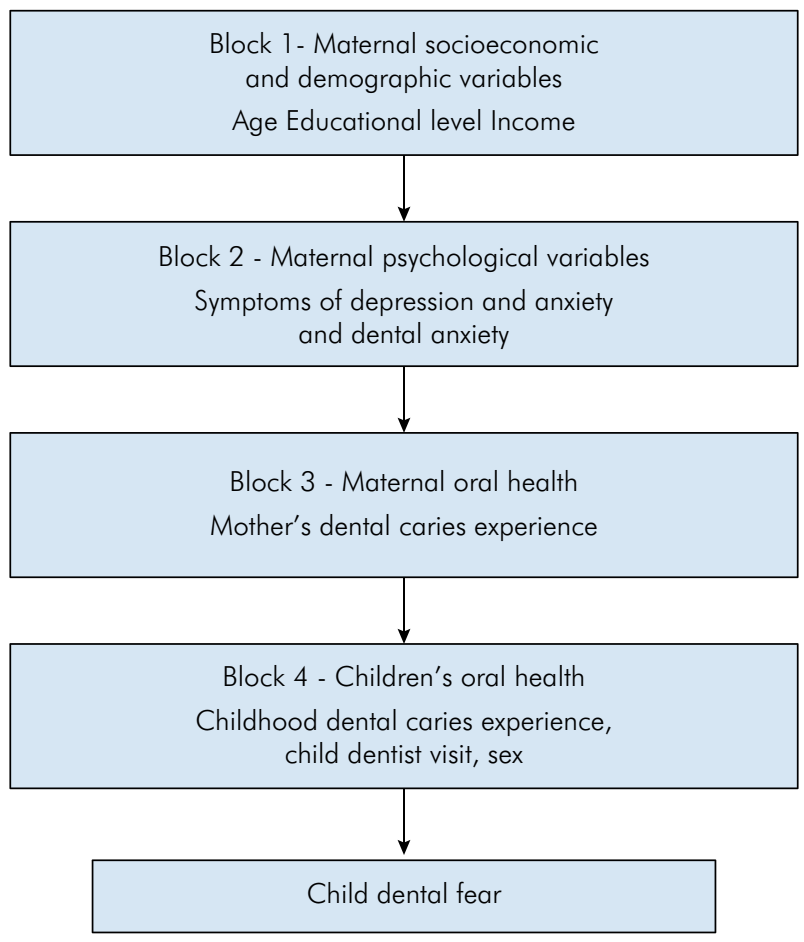

Figure 1. Theoretical model for child dental fear and psychological characteristics of mothers. 


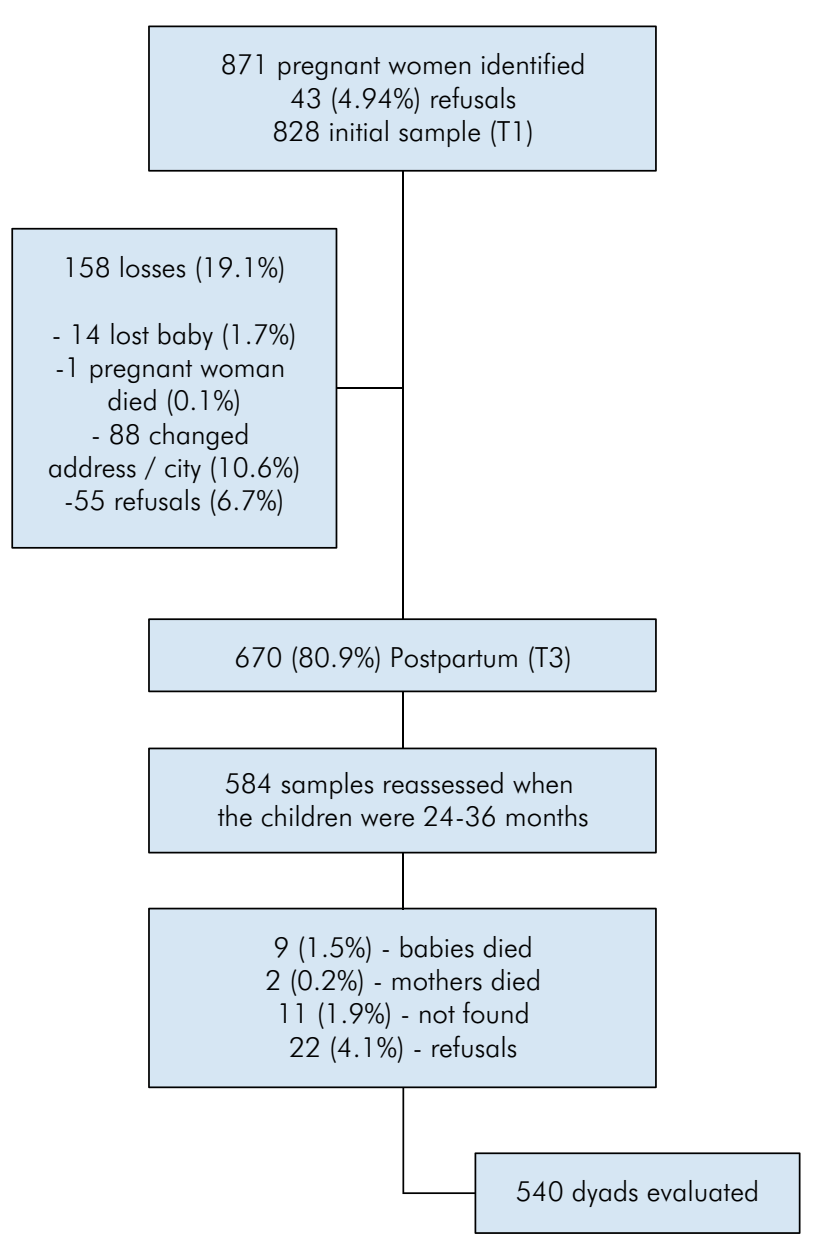

Figure 2. Flowchart with reasons for non-participation at each stage.

The prevalence of dental fear in children was $21.6 \%(n=114)$, being greater in children of younger mothers $(15-18$ years $)(p=0.031)$, and was associated with maternal dental anxiety $(p=0.022)$ and maternal caries experience $(p=0.010)$.

Table 1 states that the majority of mothers were 19-23 years old $(84.7 \%)$, for a mean age (SD) of 20.1 $( \pm 2.0)$ years, and that most of the families belonged to economic class C (69.5\%). The prevalence of dental caries was $74.4 \%$ in mothers and $15.0 \%$ in children. The presence of depressive symptoms determined at the time of data collection was $39.1 \%$, and was associated with a higher prevalence of dental fear in children, compared with children of mothers without depressive symptoms $(\mathrm{p}=0.042)$, and the prevalence of maternal anxiety symptoms was $27.8 \%$.
Table 1. Relationship between child dental fear, child characteristics and maternal psychological variables $(n=527)$. Pelotas, Brazil, 2017.

\begin{tabular}{|c|c|c|c|c|}
\hline \multirow{3}{*}{ Variable } & \multirow{2}{*}{ Total } & \multicolumn{2}{|c|}{ Child dental fear } & \multirow{3}{*}{$\mathrm{p}$} \\
\hline & & Yes & No & \\
\hline & n (\%) & n (\%) & n (\%) & \\
\hline \multicolumn{5}{|l|}{ Maternal age } \\
\hline $15-18$ years & $81(15.5)$ & $25(30.9)$ & $56(69.1)$ & \multirow{2}{*}{0.031} \\
\hline $19-23$ years & $443(84.5)$ & $89(20.1)$ & $354(79.9)$ & \\
\hline \multicolumn{5}{|c|}{ Maternal education level } \\
\hline$\leq 4$ years & $244(46.6)$ & $60(24.6)$ & $184(75.4)$ & \multirow{2}{*}{0.142} \\
\hline $5-8$ years & $280(53.4)$ & 54 (19.3) & $226(80.7)$ & \\
\hline
\end{tabular}

Maternal socioeconomic classification*

$\begin{array}{lcccc}\mathrm{a} / \mathrm{b} & 79(15.8) & 12(15.2) & 67(84.8) & \\ \mathrm{c} & 350(70.1) & 75(21.4) & 275(78.6) & 0.113 \\ \mathrm{~d} / \mathrm{e} & 70(14.1) & 18(25.7) & 52(74.3) & \end{array}$

Maternal symptoms of depression*

$\begin{array}{lllll}\text { No } & 312(60.5) & 59(18.9) & 253(81.1) & \\ \text { Yes } & 204(39.5) & 54(26.5) & 150(73.5) & 0.042\end{array}$

Maternal symptoms of anxiety*

$\begin{array}{lllll}\text { No } & 370(72.1) & 73(19.7) & 297(80.3) & 0.091 \\ \text { Yes } & 143(27.9) & 38(26.6) & 105(73.4) & \end{array}$

Maternal dental anxiety*

$\begin{array}{lrrrr}\text { Mild } & 320(62.4) & 60(18.7) & 260(81.2) & \\ \text { Moderate } & 108(21.0) & 27(25.0) & 81(75.0) & 0.022 \\ \text { Severe } & 85(16.6) & 25(29.4) & 60(70.6) & \end{array}$

Maternal caries experience

$\begin{array}{lllll}\text { No } & 132(25.0) & 18(13.6) & 114(86.4) & 0.010 \\ \text { Yes } & 395(75.0) & 96(24.3) & 299(75.7) & \end{array}$

Sex of child

$\begin{array}{lllll}\text { Male } & 257(49.0) & 58(22.6) & 199(83.9) & 0.642 \\ \text { Female } & 268(51.0) & 56(20.9) & 212(79.1) & \end{array}$

Child visited the dentist

$\begin{array}{lllll}\text { Yes } & 119(22.6) & 19(16.1) & 99(83.9) & \\ \text { No } & 407(77.4) & 95(23.3) & 312(76.7) & \end{array}$

Child caries experience

\begin{tabular}{lllll} 
Yes & $79(15.0)$ & $16(20.2)$ & $63(79.8)$ & \\
No & $448(85.0)$ & $98(21.9)$ & $350(78.1)$ & 0.747 \\
\hline
\end{tabular}

*BDI- Beck Depression Inventory (cutoff 12); ${ }^{* *}$ BAI- Beck Anxiety Inventory Chi-square test.

Values less than 527 are due to missing information 
The multivariate analysis showed that, even after the adjustments, children of mothers with symptoms of depression had a $40 \%$ higher prevalence of dental fear than children from non-symptomatic mothers. Similarly, children of mothers with dental caries experience presented a higher prevalence of dental fear than those from mothers without dental caries (Table 2).

Table 3 presents the analytic results of the trajectories of depression and anxiety from pregnancy to the time of data collection, and their relation to dental fear in the offspring. After adjustment, chronic exposure to depression symptomatology was found to have no negative impact on dental fear. In contrast, the trajectory of anxiety symptomatology was a significant factor, considering the association between mothers presenting anxiety and higher levels of dental fear in children $(p=0.004)$.

Table 2. Association between children with dental fear and characteristics of mothers and children. Crude and adjusted analyses. $(n=524)$. Pelotas, Brazil, 2017.

\begin{tabular}{|c|c|c|c|c|}
\hline \multirow{3}{*}{ Variable } & \multicolumn{4}{|c|}{ Children Dental Fear } \\
\hline & Crude & \multirow{2}{*}{$p$} & Adjusted & \multirow{2}{*}{$\mathrm{p}$} \\
\hline & $\mathrm{PR}(95 \% \mathrm{Cl})$ & & PR $(95 \% \mathrm{Cl})$ & \\
\hline \multicolumn{5}{|c|}{ Maternal symptoms of depression* } \\
\hline No & 1.00 & \multirow{2}{*}{0.042} & 1.00 & \multirow{2}{*}{0.055} \\
\hline Yes & $1.40(1.01-1.94)$ & & $1.40(0.99-1.96)$ & \\
\hline \multicolumn{5}{|c|}{ Maternal symptoms of anxiety* } \\
\hline No & 1.00 & \multirow{2}{*}{0.087} & - & \\
\hline Yes & $1.35(0.96-1.89)$ & & - & \\
\hline \multicolumn{5}{|c|}{ Maternal dental anxiety* } \\
\hline Mild & 1.00 & \multirow{3}{*}{0.019} & - & \multirow{3}{*}{ - } \\
\hline Moderate & $1.33(0.89-1.99)$ & & - & \\
\hline Severe & $1.57(1.05-2.84)$ & & - & \\
\hline \multicolumn{5}{|c|}{ Maternal caries experience* } \\
\hline No & 1.00 & \multirow{2}{*}{0.014} & 1.00 & \multirow{2}{*}{0.015} \\
\hline Yes & $1.78(1.12-2.83)$ & & $1.63(1.02-2.60)$ & \\
\hline \multicolumn{5}{|l|}{ Sex of child* } \\
\hline Female & 1.00 & \multirow{2}{*}{0.642} & - & \multirow{2}{*}{-} \\
\hline Male & $1.08(0.78-1.50)$ & & - & \\
\hline \multicolumn{5}{|c|}{ Child visited the dentist* } \\
\hline Yes & 1.00 & \multirow{2}{*}{0.104} & 1.00 & \multirow{2}{*}{0.171} \\
\hline No & $1.45(0.93-2.27)$ & & $1.36(0.87-2.13)$ & \\
\hline \multicolumn{5}{|c|}{ Child caries experience* } \\
\hline No & 1.00 & \multirow{2}{*}{0.748} & - & \\
\hline Yes & $0.93(0.58-1.48)$ & & - & - \\
\hline
\end{tabular}

\section{Discussion}

The overall results of this study showed that children whose mothers presented symptoms of depression and anxiety had a higher chance of developing dental fear. Symptoms of depression and anxiety frequently co-occur; women who report depressive symptoms are likely to also experience clinically significant symptoms of anxiety. ${ }^{4}$

According to the Diagnostic and Statistical Manual of Mental Disorders (DSM-IV), the diagnosis of depression requires the occurrence of one or more episodes of depression for a period of two weeks or more, and depressed mood or loss of interest or pleasure in almost all daily activities, along with a number of other symptoms of depression, including weight loss or gain, loss of appetite, sleep disturbances, psychomotor agitation or delay, fatigue, feelings of guilt or worthlessness, and difficulty concentrating. On the other hand, anxiety is characterized as a subjective state of feelings or reactions in the face of an unknown situation.

In the present study, the presence of depressive symptoms at the time of data-collection was 39.1\%. According to McGrath et al., ${ }^{24}$ the estimated prevalence of depression in women with children is high (10\%-42\%), and $38 \%$ of women experience depression during pregnancy. These results are in line with the prevalence of depression disorders observed in our surveyed sample. The prevalence of anxiety in our sample of adolescent mothers was $27.8 \%$.

The feeling of dental fear in children may be related to these maternal feelings, because the relational behavior of depressive mothers is characterized by low sensitivity, a restricted range of affective expression, and inconsistent support of the infant's budding engagement. Anxious mothers present intrusive behavior that is not appropriate for the infant's state, whereas depressed mothers show flat and withdrawn affects, and rarely engage in a true social exchange. Both styles deprive infants of the critical growth-promoting elements of a mother's sensitive style. ${ }^{25}$ Maternal depression diminishes the quality of parent-child interactions, bearing consequences that exert an adverse influence on the infant, such as the development of fear. Depressed mothers are unable to 
Table 3. Trajectory of depression and anxiety ever since mothers' pregnancy, and how they influence the dental fear of their offspring. ( $\mathrm{n}=507)$. Pelotas, Brazil, 2017.

\begin{tabular}{|c|c|c|c|c|}
\hline \multirow{3}{*}{ Variable } & \multicolumn{4}{|c|}{ Children dental fear } \\
\hline & \multirow{2}{*}{$\begin{array}{c}\text { Crude } \\
\text { PR }(95 \% \mathrm{Cl})\end{array}$} & \multirow[b]{2}{*}{$\mathrm{p}$} & Adjusted & \multirow{2}{*}{$\mathrm{p}$} \\
\hline & & & PR $(95 \% \mathrm{Cl})$ & \\
\hline \multicolumn{5}{|c|}{ Trajectory of depressive symptoms* } \\
\hline Never depressed & 1.00 & \multirow{4}{*}{0.002} & - & \multirow{4}{*}{-} \\
\hline Not depressed/depressed & $1.74(1.03-2.92)$ & & - & \\
\hline Depressed/not depressed & $1.79(1.17-2.72)$ & & - & \\
\hline Always depressed & $1.86(1.19-2.91)$ & & - & \\
\hline \multicolumn{5}{|l|}{ Trajectory of anxiety symptoms* } \\
\hline Never anxious & 1.00 & \multirow{4}{*}{0.002} & 1.00 & \multirow{4}{*}{0.004} \\
\hline Not anxious/anxious & $1.13(0.68-1.89)$ & & $0.90(0.51-1.59)$ & \\
\hline Anxious/ not anxious & $1.49(0.94-2.37)$ & & $1.32(0.80-2.18)$ & \\
\hline Always anxious & $2.05(1.37-3.05)$ & & $2.09(1.40-3.13)$ & \\
\hline \multicolumn{5}{|l|}{ Maternal dental anxiety* } \\
\hline Mild & 1.00 & \multirow{3}{*}{0.019} & - & \multirow{3}{*}{-} \\
\hline Moderate & $1.33(0.89-1.99)$ & & - & \\
\hline Severe & $1.57(1.05-2.84)$ & & - & \\
\hline \multicolumn{5}{|l|}{ Mother's dental caries* } \\
\hline No & 1.00 & \multirow{2}{*}{0.014} & 1.00 & \multirow{2}{*}{0.044} \\
\hline Yes & $1.78(1.12-2.83)$ & & $1.60(1.01-2.55)$ & \\
\hline \multicolumn{5}{|l|}{ Sex of the child* } \\
\hline Female & 1.00 & \multirow{2}{*}{0.642} & - & \multirow[b]{2}{*}{ - } \\
\hline Male & $1.08(0.78-1.50)$ & & - & \\
\hline \multicolumn{5}{|l|}{ Child visited the dentist* } \\
\hline Yes & 1.00 & \multirow{2}{*}{0.104} & 1.00 & \multirow{2}{*}{0.163} \\
\hline No & $1.45(0.93-2.27)$ & & $1.37(0.88-2.13)$ & \\
\hline \multicolumn{5}{|l|}{ Child dental caries* } \\
\hline No & 1.00 & \multirow{2}{*}{0.748} & - & \multirow{2}{*}{-} \\
\hline Yes & $0.93(0.58-1.48)$ & & - & \\
\hline
\end{tabular}

understand their children's affective communication, and thus fail to attune themselves adequately to it. Negative affects thus become pervasive in the dyad, and eventually stabilize the negative affect in the child. Consequently, the child will interact negatively with the mother, and mutual amplification of prolonged negative emotions will ensue. ${ }^{26}$

Dental fear is a normal emotional reaction to one or more specific threatening stimuli in a dental situation, whereas dental anxiety refers to a state of apprehension that something dreadful is going to happen in relation to dental treatment ${ }^{27}$; nevertheless, they are used as synonyms. ${ }^{13}$ The prevalence of dental fear in our study was $21.6 \%$, similar to that of Salem et al. ${ }^{28}$ who reported that children 3-4 years old showed $21.0 \%$ of prevalence of dental fear. Younger children lack cognitive maturity, and have no clear perception of real fear at these early ages; thus, what is reported by mothers is the best indicator of dental fear or anxiety in younger kids - the method used in our study.

Some previous studies have demonstrated that persistence of maternal depressive symptoms could have a greater negative impact on their children's health. ${ }^{29,30}$ The authors observed how maternal symptoms influenced the depression trajectory, leading to the development of dental fear in children, as per performance of a crude analysis; however, this association lost significance after adjustments were made. Regarding the trajectory of anxiety symptomatology, the authors observed that anxious mothers have a greater chance of having offspring with higher levels of dental fear than mothers without anxiety problems. When postpartum depression is prolonged, the adverse effects on mother-child 
bonding become more prominent. Specifically, the risk of abuse and neglect increase if the mother's depression is not treated. Moreover, these effects continue to impact the mother-child dyad in the long term. ${ }^{31}$

In our study, mothers with higher levels of dental caries were more likely to have children with higher development of dental fear. A vicious cycle in relation to dental fear has long been proposed, whereby dental fear leads directly to avoidance of dental visits, resulting in deterioration of oral health, and, in turn, to problem-oriented office visits. This chain of events serves to maintain or exacerbate the person's level of dental fear. ${ }^{13}$

Maternal depression is associated with poor care of the mother's own health, and, consequently, with neglect of her child's health. Moreover, maternal depression promotes suboptimal interaction between mothers and infants, which may, in turn, have an adverse effect on the cognitive, social, and emotional development of the child. Such poor interaction leads to hostile behavior; parent-child hostility gives rise to fear and increases the likelihood of aggressive behavior and anxiety in the child. ${ }^{7}$

In the present study, the mothers reported that their children were afraid, and this could be considered a limitation, because individuals with symptoms of depression are more likely to draw strong negative conclusions. ${ }^{32}$ However, the instruments used for the psychological diagnosis of the mothers were applied by psychologists, and those used to obtain information related to child's dental fear were validated. Parents, especially mothers, can predict their children's dental anxiety level using universally acceptable measuring schedules, especially for young children. ${ }^{33}$ Another limitation relates to the selected mothers who were attending the Brazilian public health system for prenatal care. These mothers have lower incomes and fewer years of education than those who receive prenatal care in private health services.

Nevertheless, the present study is unique in its investigation of the association between symptoms of depression/anxiety in mothers and the occurrence of dental fear in their young children. Some studies in the literature have shown a relationship between depression and general fear in children, ${ }^{8,34}$ advancing the hypothesis that depression could also influence dental fear, as was confirmed in our study. Another important strength of this study is the evaluation of maternal depressive and anxiety symptoms at two moments of life. Furthermore, the longitudinal design provided higher data reliability and the opportunity to investigate the exposure before measuring the outcome.

Breaking the vicious cycle of fear, anxiety and depression requires a multidisciplinary approach that involves both mental health and community dentistry professionals. It is important that the children of depressed mothers be well cared for, as regards health indicators such as psychological factors, since a negative maternal influence makes these children more vulnerable. The mother-child dyad should be included in healthcare settings. Knowledge of dental anxiety antecedents is needed to design effective community programs aimed at preventing dental fear and its oral health-related consequences. New investigations that can assess dental fear directly in children and measure other outcomes longitudinally may further the findings on the subject.

\section{Conclusion}

The symptoms of depression at data collection time and the persistence of symptoms of anxiety in adolescent mothers were associated with dental fear in children. More attention should be given to mother-child dyads in cases when mothers have mental disorders, to prevent them from impairing the general and oral health of their children.

\section{Acknowledgement}

The authors would like to thank the State Funding Agency (FAPERGS) for its grant (\#11/1189-4), and for the first author scholarship (VPPC), as well as the Brazilian Council for Improvement of Research CNPq (14/2012- no. 483669/2012-1). The authors are grateful to the graduate and undergraduate students that participated in the fieldwork and to the Catholic University of Pelotas. Lastly, we would like to honor Professor Dione Dias Torriani (in memoriam) for her commitment and dedication to this project. 


\section{References}

1. Parsons CE, Young KS, Rochat TJ, Kringelbach ML, Stein A. Postnatal depression and its effects on child development: a review of evidence from low- and middle-income countries. Br Med Bull. 2012;101(1):57-79. https://doi.org/10.1093/bmb/ldr047

2. Gavin AR, Lindhorst T, Lohr MJ. The prevalence and correlates of depressive symptoms among adolescent mothers: results from a 17-year longitudinal study. Women Health. 2011;51(6):525-45. https://doi.org/10.1080/03630242.2011.606355

3. Lee AM, Lam SK, Sze Mun Lau SM, Chong CS, Chui HW, Fong DY. Prevalence, course, and risk factors for antenatal anxiety and depression. Obstet Gynecol. 2007;110(5):1102-12. https://doi.org/10.1097/01.AOG.0000287065.59491.70

4. Wenzel A, Haugen EN, Jackson LC, Brendle JR. Anxiety symptoms and disorders at eight weeks postpartum. J Anxiety Disord. 2005;19(3):295-311. https://doi.org/10.1016/i.janxdis.2004.04.001

5. Apter-Levy Y, Feldman M, Vakart A, Ebstein RP, Feldman R. Impact of maternal depression across the first 6 years of life on the child's mental health, social engagement, and empathy: the moderating role of oxytocin. Am J Psychiatry. 2013;170(10):1161-8. https://doi.org/10.1176/appi.ajp.2013.12121597

6. Bowlby J. Attachment and loss. New York: Basic Books; 1969.

7. Velders FP, Dieleman G, Henrichs J, Jaddoe VW, Hofman A, Verhulst FC et al. Prenatal and postnatal psychological symptoms of parents and family functioning: the impact on child emotional and behavioural problems. Eur Child Adolesc Psychiatry. 2011;20(7):341-50. https://doi.org/10.1007/s00787-011-0178-0

8. Turner SM, Beidel DC, Roberson-Nay R. Offspring of anxious parents: reactivity, habituation, and anxiety-proneness. Behav Res Ther. 2005;43(10):1263-79. https://doi.org/10.1016/i.brat.2004.09.005

9. Sarracino D, Presaghi F, Degni S, Innamorati M. Sex-specific relationships among attachment security, social values, and sensation seeking in early adolescence: implications for adolescents' externalizing problem behaviour. J Adolesc. 2011;34(3):541-54 https://doi.org/10.1016/i.adolescence.2010.05.013

10. Corkey B, Freeman R. Predictors of dental anxiety in six-yearold children: findings from a pilot study. ASDC J Dent Child. 1994;61(4):267-71.

11. Themessl-Huber M, Freeman R, Humphris G, MacGillivray $S$, Terzi N. Empirical evidence of the relationship between parental and child dental fear: a structured review and meta-analysis. Int J Paediatr Dent. 2010;20(2):83-101. https://doi.org/10.1111/j.1365-263X.2009.00998.x

12. Torriani DD, Ferro RL, Bonow ML, Santos IS, Matijasevich A, Barros AJ et al. Dental caries is associated with dental fear in childhood: findings from a birth cohort study. Caries Res. 2014;48(4):263-70. https://doi.org/10.1159/000356306
13. Armfield JM. What goes around comes around: revisiting the hypothesized vicious cycle of dental fear and avoidance. Community Dent Oral Epidemiol. 2013;41(3):279-87. https://doi.org/10.1111/cdoe.12005

14. Stenebrand A, Wide Boman U, Hakeberg M. Dental anxiety and symptoms of general anxiety and depression in 15-year-olds. Int J Dent Hyg. 2013;11(2):99-104. https://doi.org/10.1111/j.1601-5037.2012.00551.x

15. Coelho FM, Pinheiro RT, Silva RA, Quevedo LA, Souza LDM, Matos MB et al. Parental bonding and suicidality in pregnant teenagers: a population-based study in southern Brazil. Soc Psychiatry Psychiatr Epidemiol. 2014;49(8):1241-8. https://doi.org/10.1007/s00127-014-0832-1

16. Goettems ML, Correa MB, Vargas-Ferreira F, Torriani DD, Marques M, Domingues MR et al. Methods and logistics of a multidisciplinary survey of schoolchildren from Pelotas, in the Southern Region of Brazil. Cad Saúde Pública. 2013;29(5): 867-78. https://doi.org/10.1590/S0102-311X2013000500005

17. Neverlien PO. Assessment of a single-item dental anxiety question. Acta Odontol Scand. 1990;48(6):365-9. https://doi.org/10.3109/00016359009029067

18. Oliveira MM, Colares V. The relationship between dental anxiety and dental pain in children aged 18 to 59 months: a study in Recife, Pernambuco State, Brazil. Cad Saúde Pública. 2009;25(4):743-50. https://doi.org/10.1590/S0102-311X2009000400005

19. Beck A. Inventário de ansiedade de Beck. In: Cunha JA. Manual da versão em português das Escalas Beck. São Paulo: Casa do Psicólogo; 2001. paginação.

20. Gomes-Oliveira MH, Gorenstein C, Lotufo Neto F, Andrade LH, Wang YP. Validation of the Brazilian Portuguese version of the Beck Depression Inventory-II in a community sample. Rev Bras Psiquiatr. 2012;34(4):389-94. https://doi.org/10.1016/i.rbp.2012.03.005

21. Corah NL. Development of a dental anxiety scale. J Dent Res. 1969;48(4):596. https://doi.org/10.1177/00220345690480041801

22. World Health Organization - WHO. The International Classification of Diseases and related health problems. 10th ed. Geneva: World Health Organization; 1992.

23. Associação Brasileira de Empresas de Pesquisa - ABEP. São Paulo; 2012 [cited 2016 Nov 11]. Available from: http://www.abep.org

24. McGrath JM, Records K, Rice M. Maternal depression and infant temperament characteristics. Infant Behav Dev. 2008;31(1):7180. https://doi.org/10.1016/j.infbeh.2007.07.001

25. Feldman R, Granat A, Pariente C, Kanety H, Kuint J, Gilboa-Schechtman E. Maternal depression and anxiety across the postpartum year and infant social engagement, fear regulation, and stress reactivity. J Am Acad Child Adolesc Psychiatry. 2009;48(9):919-27. https://doi.org/10.1097/CHI.0b013e3181b21651 
26. Santona A, Tagini A, Sarracino D, De Carli P, Pace CS, Parolin L et al. Maternal depression and attachment: the evaluation of mother-child interactions during feeding practice. Front Psychol. 2015;6:1235. https://doi.org/10.3389/fpsyg.2015.01235

27. Klingberg G, Broberg AG. Dental fear/anxiety and dental behaviour management problems in children and adolescents: a review of prevalence and concomitant psychological factors. Int J Paediatr Dent .2007;17(6):

391-406. https://doi.org/10.1111/j.1365-263X.2007.00872.x

28. Salem K, Kousha M, Anissian A, Shahabi A. Dental Fear and Concomitant Factors in 3-6 Year-old Children. J Dent Res Dent Clin Dent Prospects. 2012;6(2):70-4. https://doi.org/10.5681/joddd.2012.015

29. Campbell SB, Morgan-Lopez AA, Cox MJ, McLoyd VC. A latent class analysis of maternal depressive symptoms over 12 years and offspring adjustment in adolescence. J Abnorm Psychol. 2009;118(3):479-93. https://doi.org/10.1037/a0015923

30. Keller MB, Lavori PW, Rice J, Coryell W, Hirschfeld RM. The persistent risk of chronicity in recurrent episodes of nonbipolar major depressive disorder: a prospective follow-up. Am J Psychiatry. 1986;143(1):24-8. https://doi.org/10.1176/ajp.143.1.24

31. Ohoka H, Koide T, Goto S, Murase S, Kanai A, Masuda $T$ et al. Effects of maternal depressive symptomatology during pregnancy and the postpartum period on infant-mother attachment. Psychiatry Clin Neurosci. 2014;68(8):631-9. https://doi.org/10.1111/pcn.12171

32. LaRosa AC, Glascoe FP, Macias MM. Parental depressive symptoms: relationship to child development, parenting, health, and results on parent-reported screening tools. J Pediatr. 2009;155(1):124-8.

33. Folayan $\mathrm{MO}$, Idehen $\mathrm{EE}$, Ojo $\mathrm{OO}$. Dental anxiety in a subpopulation of African children: parents ability to predict and its relation to general anxiety and behaviour in the dental chair. Eur J Paediatr Dent. 2004;5(1):19-23.

34. Sugawara M, Kitamura T, Toda MA, Shima S. Longitudinal relationship between maternal depression and infant temperament in a Japanese population. J Clin Psychol. 1999;55(7):869-80. https://doi.org/10.1002/(SICI)10974679(199907)55:7<869::AID-JCLP8>3.0.CO;2-F 